\title{
G (2) \\ Pretreatment of NPMSCs with Appropriate Concentration of H2O2 Enhances its Ability to Treat IVDD
}

\section{Yuyao Zhang ( $\nabla$ zhangyuyao@tmmu.edu.cn )}

Third Military Medical University Second Affiliated Hospital: Xinqiao Hospital https://orcid.org/00000002-6584-0778

\section{Zhilei Hu}

Third Military Medical University Second Affiliated Hospital: Xinqiao Hospital

\section{Yuhan Qi}

China Academy of Chinese Medical Sciences

\section{Haiyin Li}

Third Military Medical University Second Affiliated Hospital: Xinqiao Hospital

\section{Xian Chang}

Third Military Medical University Second Affiliated Hospital: Xinqiao Hospital

\section{Xiaoxin Gao}

Third Military Medical University Second Affiliated Hospital: Xinqiao Hospital

Chenhao Liu

Third Military Medical University Second Affiliated Hospital: Xinqiao Hospital

\section{Yueyang Li}

Third Military Medical University Second Affiliated Hospital: Xinqiao Hospital Jinhui Lou

Third Military Medical University Second Affiliated Hospital: Xinqiao Hospital

\section{Yu Zhai}

Third Military Medical University Second Affiliated Hospital: Xinqiao Hospital

\section{Changqing Li}

Third Military Medical University Second Affiliated Hospital: Xinqiao Hospital https://orcid.org/00000002-0029-2336

\section{Research Article}

Keywords: NPMSCs, $\mathrm{H} 2 \mathrm{O} 2$, pretreatment, transplantation, IVDD

Posted Date: January 17th, 2022

DOI: https://doi.org/10.21203/rs.3.rs-1155890/v1 
License: (c) (i) This work is licensed under a Creative Commons Attribution 4.0 International License. Read Full License 


\section{Abstract}

Background: Nucleus pulposus mesenchymal stem cells (NPMSCs) transplantation is a promising treatment for intervertebral disc degeneration (IVDD). However, the transplanted NPMSCs exhibited weak cell proliferation, high cell apoptosis, and low ability to resist the harsh microenvironment of the degenerated intervertebral disc. There is an urgent need in exploring feasible methods to enhance the therapeutic efficacy of NPMSCs transplantation.

Objective: To identify the optimal concentration for NPMSCs pretreatment with hydrogen peroxide $\left(\mathrm{H}_{2} \mathrm{O}_{2}\right)$ and explore the therapeutic efficacy of NPMSCs transplantation using $\mathrm{H}_{2} \mathrm{O}_{2}$ pretreatment in IVDD.

Methods: Rat NPMSCs were pretreated with different concentrations of $\mathrm{H}_{2} \mathrm{O}_{2}$. The proliferation, ROS level, and apoptosis of NPMSCs were detected by CCK-8 test, EdU staining, and flow cytometry in vitro. The underlying signaling pathways were explored utilizing western blot. A rat needle-puncture stimulated IVDD model was established. X-ray, histological staining, and multi-mode small animal live imaging system were performed to evaluate the therapeutic effect of $\mathrm{H}_{2} \mathrm{O}_{2}$-pretreated NPMSCs in vivo.

Results: $75 \mu \mathrm{M} \mathrm{H}_{2} \mathrm{O}_{2}$ pretreated NPMSCs demonstrated the strongest elevated cell proliferation by inhibiting the Hippo pathway. Meanwhile, $75 \mathrm{\mu M} \mathrm{H}_{2} \mathrm{O}_{2}$ pretreated NPMSCs exhibited significantly enhanced anti-oxidative stress ability, which is related to downregulated Brd4, Keap1, and upregulated Nrf2. $75 \mu \mathrm{M} \mathrm{H}_{2} \mathrm{O}_{2}$ pretreated NPMSCs also exhibited distinctly declined apoptosis. In vivo experiments results verified that $75 \mu \mathrm{M} \mathrm{H}_{2} \mathrm{O}_{2}$ pretreated NPMSCs-transplanted rats exhibited enhanced disc height index (DHI\%) and better histological morphology, which means $75 \mu \mathrm{M} \mathrm{H}_{2} \mathrm{O}_{2}$ pretreated NPMSCs can better adapt to the environment of degenerative intervertebral discs and promote the repair of IVDD.

Conclusions: Pretreatment with $75 \mu \mathrm{M} \mathrm{H}_{2} \mathrm{O}_{2}$ was the optimal concentration to improve the ability of proliferation, anti-oxidative stress, and anti-apoptosis of transplanted NPMSCs, which is expected to provide a new feasible method to improve the stem cell therapy efficacy of IVDD.

\section{Introduction}

IVDD is an important cause of low back pain (LBP) and lower extremity dysfunction, which imposes a heavy economic burden on society[1, 2]. The intervertebral disc is an important connection structure between the vertebral bodies that consisted of the nucleus pulposus, the annulus fibrosus, and the upper and lower cartilage endplate, which can maintain the amplitude of spinal motion and withstand mechanical pressure[3]. When the intervertebral disc undergoes gradual degeneration, the number of nucleus pulposus cells and the anabolic processes decrease, resulting in a series of clinical symptoms such as backache, numbness, and lower limb pain[4]. Although surgery is a commonly chosen method for palliating symptoms, it failed to restore the biological and mechanical functions of the intervertebral disc, and may even alter the biomechanical function of the spine, which may lead to further degeneration 
of the adjacent intervertebral disc[5,6]. Therefore, it is necessary to explore new feasible strategies to treat IVDD.

Stem cell transplantation has become a promising therapeutic method utilized to treat IVDD experimentally and clinically in recent years[7, 8]. The intervertebral disc is recognized as an immuneexempt area, and this feature makes it possible to use exogenous stem cells to treat $\operatorname{IVDD}[9,10]$. Extensive researches have shown that a variety of stem cells can directly differentiate into nucleus pulposus cells, and facilitate the function of degenerative nucleus pulposus cells through a paracrine manner when transplanted into the degenerative intervertebral disc[11-14]. Recent studies have identified NPMSCs with mesenchymal stem cell characteristics in the nucleus pulposus tissue, which possess a stronger ability to differentiate into nucleus pulposus cells and withstand the microenvironment of the intervertebral disc compared with commonly used stem cells such as bone marrow mesenchymal stem cells (BMMSCs) and adipose mesenchymal stem cells (ADMSCs)[15-17]. However, the low viability of transplanted stem cells at the transplant site has become a bottleneck for stem-cell based IVDD therapy. The intervertebral disc is the largest tissue without blood supply in the whole body, and the degenerated intervertebral disc exhibit a harsh microenvironment with low nutrition, low $\mathrm{pH}$, high mechanical pressure, and high osmotic pressure, coupled with distinct oxidative stress and local inflammation. Therefore, the transplanted cells will suffer cell cycle arrest and considerable cell death, which immensely undermine the effect of stem cell transplantation and even lead to transplantation failure[18-20].

A large number of methods have been explored to improve the therapeutic effect of transplanted stem cells in IVDD treatment, including conjunction with biological scaffolds, hydrogel materials, genetic modification, and cellular pretreatment, and pretreatment of stem cells with the mimetic harsh environment (e.g., hypoxia, acid, mechanical intervention) can improve their post-engraftment survival and differentiation characteristics[21-23]. Among them, pretreating transplanted cells with $\mathrm{H}_{2} \mathrm{O}_{2}$ is convenient to obtain and simple to operate. Previous studies have shown that pretreatment with an appropriate concentration of $\mathrm{H}_{2} \mathrm{O}_{2}$ can significantly improve the proliferation, paracrine manner, antiapoptotic ability, and therapeutic effect of MSCs in liver fibrosis, skin wound, and myocardial infarction[24-26]. However, a high concentration of $\mathrm{H}_{2} \mathrm{O}_{2}$ is cytotoxic and will cause the increase of reactive oxygen species (ROS), which may lead to irreversible oxidative damage to the cells[27, 28]. Therefore, exploring the optimal concentration of $\mathrm{H}_{2} \mathrm{O}_{2}$ pretreatment is of great significance for improving the effect of NPMSCs in the treatment of IVDD.

In this study, the optimal $\mathrm{H}_{2} \mathrm{O}_{2}$ concentration for pretreatment of NPMSCs was explored. We found that $75 \mu \mathrm{M} \mathrm{H}_{2} \mathrm{O}_{2}$ pretreated NPMSCs demonstrated the strongest elevated cell proliferation, enhanced antioxidative stress ability, distinctly declined apoptosis. These effects may be related to the Hippo signaling pathway, Keap1-Nrf2 signaling pathway. in vivo experiments verified that $75 \mu \mathrm{M} \mathrm{H}_{2} \mathrm{O}_{2}$ pretreated NPMSCs exhibited the strongest therapeutic effects. These results demonstrate that $75 \mu \mathrm{M} \mathrm{H}_{2} \mathrm{O}_{2}$ pretreatment of NPMSCs enhances its ability to treat IVDD. 


\section{Materials And Methods \\ Ethical statement}

Animal experiments were performed on 8-week-old male Sprague Dawley (SD) rats $(n=60)$ provided by the Animal Center of the Xinqiao Hospital. All experiments were approved by the Ethics Committee of the Army Medical University.

\section{Cell preparation}

NPMSCs were extracted from the nucleus pulposus tissue of 30 rats. Briefly, rats were properly anesthetized with $2 \%$ pentobarbital $(50 \mathrm{mg} / \mathrm{kg})$, and then the caudal vertebrae were isolated after removing the skin, ligaments, and muscle tissues under aseptic conditions. The nucleus pulposus tissue was separated from the caudal intervertebral disk and was then Digested with $0.2 \%$ type II collagenase (C2-BIOC, Sigma-Aldrich, USA) for approximately $2 \mathrm{~h}$ at $37^{\circ} \mathrm{C}$, followed by centrifugation at $400 \mathrm{~g}$ for 5 min at room temperature. The supernatant was discarded and the sediment was suspended and cultured in a standard mesenchymal stem cell growth medium (HUBMX-90011, Guangzhou, China). NPMSCs were placed in a humidified chamber in a $5 \% \mathrm{CO}_{2}$-air mixture at $37^{\circ} \mathrm{C}$. The medium was changed every $3-4$ days. Cells were subcultured when they reached a confluence of $80-90 \%$. NPMSCs from the third generations were used throughout the experiment.

\section{Detection of cell surface markers}

NPMSCs were digested with $0.25 \%$ trypsin (SH30042, HyClone, Logan, USA) and suspended in phosphate buffer solution (PBS) at $5 \times 10^{5} \mathrm{cell} / \mathrm{ml}$. Further, $100 \mu \mathrm{l}$ cell suspension solution was aliquoted per tube and incubated, respectively, with a solution of FITC-conjugated-CD34, CD45, CD73, CD90, and CD105 (all from Bioworld, Minnesota, USA) at room temperature for $30 \mathrm{~min}$. Isotype control was used in each case. After incubation, the cells were washed with PBS for three times, and then centrifuged at $4{ }^{\circ} \mathrm{C}$ at $250 \mathrm{~g}$ for $5 \mathrm{~min}$. The supernatant was discarded and the cells were re-suspended in $500 \mu \mathrm{l}$ of PBS prior flow cytometry analyses (Gallios, BECKMAN, Germany).

\section{Detection of multilineage differentiation ability}

The multilineage differentiation ability of NPMSCs was detected using an osteogenic differentiation induction kit (RASMX-90021, Cyagen Biosciences, Suzhou, China), a chondrogenic differentiation induction kit (RASMX-90041/90042, Cyagen Biosciences, Suzhou, China) and an adipogenic induction differentiation kit (RASMX-90031, Cyagen Biosciences, Suzhou, China). After 21 days of induction, NPMSCs were fixed with 4\% paraformaldehyde (P0099, Beyotime, Shanghai, China) for 30 minutes. Then, 
Alizarin Red staining, Oil Red 0 staining, and Alcian Blue staining were performed according to the instructions.

\section{Cell Counting Kit-8 assay}

The cell viability of the NPMSCs was detected using cell counting kit-8 (C0038, Beyotime, Shanghai, China). NPMSCs were seeded into 96 -well plates at a density of $5 \times 10^{3}$ cells. NPMSCs were able to grow adherent in the plates after one night's culture. Then, $\mathrm{H}_{2} \mathrm{O}_{2}$ (323381, Sigma-Aldrich, USA) was added to the medium for $12 \mathrm{~h}$ at the concentration of $25,50,75,100,150,200,300 \mu \mathrm{M}$. The medium was replaced with the fresh medium. After that, $10 \mu$ l CCK-8 reagent was added to each well and incubated at $37^{\circ} \mathrm{C}$ for $2 \mathrm{~h}$. A spectramax (M2, MOLECULAR DEVICE, USA) was used to detect the optical density (OD) values at a wavelength of $450 \mathrm{~nm}$. Each trial was repeated 3 times.

\section{EdU staining assay}

The cell proliferation activity was detected using the EdU-555 cell proliferation detection kit (C0075S, Beyotime, Shanghai, China). The cells were inoculated into 6 -well plates at a density of $2 \times 10^{5}$ cells per well. The cells were then treated with $\mathrm{H}_{2} \mathrm{O}_{2}$ at the concentration of $25,50,75,100,150,200$, and $300 \mu \mathrm{M}$ for $12 \mathrm{~h}$. Meanwhile, we designed four treatment methods for further exploration: untreated group, $75 \mu \mathrm{M}$ $\mathrm{H}_{2} \mathrm{O}_{2}$ treatment for $12 \mathrm{~h}, 300 \mu \mathrm{M} \mathrm{H}_{2} \mathrm{O}_{2}$ treatment for $12 \mathrm{~h}$, and $75 \mu \mathrm{M} \mathrm{H}_{2} \mathrm{O}_{2}$ treatment for $12 \mathrm{~h}$ and then $300 \mu \mathrm{M} \mathrm{H}_{2} \mathrm{O}_{2}$ treatment for $12 \mathrm{~h}$. $2 \mathrm{ml}$ of $10 \mu \mathrm{M} \mathrm{EdU}$ reagent was added to each well and incubated for 2 h. Cells were fixed at room temperature for $15 \mathrm{~min}$ with $2 \mathrm{ml} 4 \%$ paraformaldehyde. $2 \mathrm{ml}$ of immunostaining strong permeability solution (P0097, Beyotime, Shanghai, China) was added to each well and incubated for $15 \mathrm{~min}$. $2 \mathrm{ml}$ of Click Additive Solution was added to each well and incubated for $30 \mathrm{~min}$ at room temperature (shield from light). The nuclei were stained with Hoechst 33358 solution (C0021, Solarbio, Beijing, China). Immunofluorescent staining images were captured by the fluorescent microscope (Olympus, Tokyo, Japan).

\section{Western Blot}

The protein of NPMSCs was extracted by radio-immunoprecipitation assay (RIPA) solution (P0013B, Beyotime, Shanghai, China) containing 2\% phenylmethanesulfonyl fluoride (PMSF) (ST507, Beyotime, Shanghai, China) and $2 \%$ phosphatase inhibitor (P1082, Beyotime, Shanghai, China). The protein was then centrifuged at $4{ }^{\circ} \mathrm{C}$ and $12,000 \mathrm{~g}$ for $5 \mathrm{~min}$ to collect the supernatant. Protein concentration was detected by bicinchoninic acid (BCA) protein concentration assay kit (PC0020, Solarbio, Beijing, China). Then protein loading buffer (Beyotime Biotechnology, Shanghai, China, P0015L) was added to each sample and heated in a boiling water bath for $5 \mathrm{~min}$. The protein was separated in $12 \%$ sodium saltpolyacrylamide gel, then the protein was transferred to polyvinylidene fluoride (PVDF) membranes (ISEQ00010, Merck Millipore, Darmstadt, Germany). The membranes were soaked with 5\% skim milk 
powder (P0216, Beyotime Biotechnology, Shanghai, China) for $1 \mathrm{~h}$ at room temperature and incubated with corresponding antibodies at $4^{\circ} \mathrm{C}$ overnight. After washing with TBS with Tween-20 (TBST), the membranes were immersed by the corresponding horseradish peroxidase-labeled secondary antibody (diluted concentration 1:500) and incubated at room temperature for $1 \mathrm{~h}$. The ECL luminescence kit (1705060, BIO-RAD, CA, USA) and gel imaging system (BIO-RAD, CA, USA) were utilized to visualize protein content. Protein bands were analyzed using Image $\mathrm{J}$ software (National Institute of Health, USA). All results were quantified and normalized to $\beta$-Actin. The antibodies used are as follows: cyclin D1 (ab134175), P16 (ab51243), B-Actin (ab8227), Cytochrome C (ab133504), Brd4 (ab75898), Keap1 (ab119403) and Nrf2 (ab92946) from Abcam (Cambridge, UK). cleaved-caspase 3 (9664T), p-Lats1 (9157), p-Mst1 (49332), p-YAP (13008T), and YAP (14074T) from CST (Shanghai, China). Bcl-2 (26593-1AP) and Bax (60267-1-lg) from Proteintech (Chicago, USA).

\section{Detection of ROS}

ROS level in cells was detected using the ROS detection kit (S0033M Beyotime, Biotechnology, Shanghai, China). $2 \mathrm{ml}$ of $10 \mu \mathrm{M}$ DCFH-DA (diluted by serum-free medium) was added to each well, and the cells were incubated at $37^{\circ} \mathrm{C}$ for $20 \mathrm{~min}$ (shield from light). The cells were then washed with the serum-free medium for 3 times to remove the unloaded probes. After that, the cells were collected and the production of ROS was detected by flow cytometry.

\section{Detection of mitochondrial membrane potential}

Mito-Tracker Red CMXRos (C1049B Beyotime, Biotechnology, Shanghai, China) was used to detect mitochondrial membrane potential. Briefly, NPMSCs were inoculated into 6-well plates at a density of $2 \times 10^{5}$ cells per well and treated with $\mathrm{H}_{2} \mathrm{O}_{2}$ at concentrations of 75 and $300 \mu \mathrm{M}$ for $24 \mathrm{~h}$, with or without $75 \mu \mathrm{M} \mathrm{H}_{2} \mathrm{O}_{2}$ for $12 \mathrm{~h}$ prior to $300 \mu \mathrm{M} \mathrm{H}_{2} \mathrm{O}_{2}$ treatment. Then $1 \mathrm{ml}$ of Mito-Tracker Red CMXRos working solution was added to each well and incubated at $37^{\circ} \mathrm{C}$ for $30 \mathrm{~min}$ (shield from light). The nuclei were stained with the Hoechst 33358 staining solution. The staining was observed under a laser confocal microscope (LSM880, ZEISS, Germany).

\section{Detection of apoptosis rate}

The rate of apoptosis was detected using the Annexin VPE/7-AAD apoptosis detection kit (BD Pharmingen, Franklin Lakes, NJ, USA). NPMSCs were collected and resuspended in binding buffer at a concentration of $5 \times 10^{6} \mathrm{cells} / \mathrm{ml}$. Then $100 \mu \mathrm{l}$ cell suspension was transferred to the test tube and $5 \mu \mathrm{l}$ of Annexin VPE and $5 \mu$ of 7-AAD were added. After incubating at room temperature for $15 \mathrm{~min}$ (shield from light), $400 \mu$ l binding buffer was added to each sample and the apoptosis rate was detected by flow cytometry. 


\section{Labeling of NPMSCs with green fluorescent protein (GFP)}

Lentiviral vectors expressing GFP (GV493, GeneChem, Shanghai, China) were transfected in NPMSCs according to the manufacturer's instructions. The multiplicity of infection (MOI) was set at 20 and the transfection time was set at $18 \mathrm{~h} .5 \mu \mathrm{g} / \mathrm{ml}$ puromycin (ST551, Beyotime, Shanghai, China) was used to select stably transfected NPMSCs.

\section{Establishment of IVDD model in rats}

30 healthy male SD rats aged 8 weeks were randomly selected for animal experiments. Rats were fasted for $12 \mathrm{~h}$ before surgery, and water was forbidden for $4 \mathrm{~h}$ before surgery. Then the rats were anesthetized by intraperitoneal injection of $2 \%$ pentobarbital $(50 \mathrm{mg} / \mathrm{kg}$ ). The tail skin of rats was sterilized with iodophor for 3 times, and percutaneous intervertebral disc puncture was performed with no. 20 needle at coccyx 6-7 (CO6-7) level[29]. The needle was vertically inserted at a depth of $5 \mathrm{~mm}$ and rotated through 360 degrees for 30 seconds before exiting, Surgical areas were then sterilized with iodophor again. Rats were provided with food and water $12 \mathrm{~h}$ after the operation to prevent intestinal paralysis.

\section{NPMSCs transplantation in IVDD rats}

4 weeks after the operation, X-ray was used to verify if the IVDD models were successfully created. After excluding 3 rats that died accidentally and 3 rats that failed to induce IVDD, the remaining 24 rats with obvious IVDD were randomly divided into 4 groups: Untreated group (6 rats) were treated without any treatment, PBS injection group (6 rats) were injected with $2 \mu \mathrm{PBS}$ at C06-7, normal cells group (6 rats) were injected with labeled NPMSCs ( $5 \times 10^{4}$ cells, suspended in PBS) at C06-7, and pretreated cells group were injected with labeled NPMSCs $\left(5 \times 10^{4}\right.$ cells, suspended in PBS) after $75 \mu \mathrm{M}$ pretreatment for $12 \mathrm{~h}$ at C06-7. PBS and cells were injected through a microsyringe ( $25 \mu \mathrm{l}$, Gaoge, Shanghai, China).

\section{Disc height measurement}

A multi-mode small animal live imaging system (Xtremell, BRUKER, Belgium) was used to obtain X-ray images of rats. Rats were anesthetized by intraperitoneal injection of $2 \%$ pentobarbital $(50 \mathrm{mg} / \mathrm{kg})$, Then the rats were fixed on the tray and put into the apparatus. The parameters were as follows: Modality (XRay), Background (None), Illumination (X-Ray), Filters (X-Ray $0.4 \mathrm{~mm}, \mathrm{KVP} 45$, Excitation 0, Emission 0), Exposure time (1.2 s), FOV (15 cm), fStop (2), Bin (1×1), Focal Plane $(0 \mathrm{~mm})$, Focal Zone (X-Ray). Finally, Image $\mathrm{J}$ was used to measure the three longitudinal lines of the intervertebral disc and the two adjacent upper and lower vertebral bodies, and then calculate the DHI\% according to the method recorded in previous research[9] to evaluate the degree of IVDD. 


\section{Histological analyzes of the caudal intervertebral disc}

At 60 days after treatment, the caudal vertebrae of rats were collected. The samples were fixed in $4 \%$ paraformaldehyde solution for $48 \mathrm{~h}$, Then, rapid bone tissue decalcification solution (BB-23619, Bestbio, Shanghai, China) was used for decalcification for 2 days. Then the samples were dehydrated with ethanol solutions of different concentrations (75\%, 85\%, 95\% and 100\%). Paraffin sections (6 um) were prepared and stained with Hematoxylin Eosin staining Kit (G1120, Solarbio, Beijing, China) and Modified Safranine 0-Fast Green FCF Stain Kit (G1371, Solarbio, Beijing, China) to evaluate the degree of IVDD in each group. Three observers blindly observed the shape and structure of the intervertebral disc and the type and number of cells in the intervertebral disc and scored using the grading scale (Supplementary Table S1) reported in the previous research[30].

\section{Fluorescence imaging of rats in vivo}

A multi-mode small animal live imaging system (Xtremell, BRUKER, Belgium) was used to obtain fluorescence images of rats. Rats were anesthetized by intraperitoneal injection of $2 \%$ pentobarbital (50 $\mathrm{mg} / \mathrm{kg}$ ), Then we fixed the rats on the tray and put them into the apparatus. The parameters were as follows: Modality (Fluorescence), Background (None), Illumination (Multi-wavelength), Filters (X-Ray 0 $\mathrm{mm}, \mathrm{KVP} 45$, Excitation 470, Emission 535), Exposure time (2 s), FOV (15 cm), fStop (2), Bin (2×2), Focal Plane (0 mm), Focal Zone (Tray).

\section{Statistical analysis}

All the experiments were repeated three times with at least triplicated samples. The results were presented as mean \pm standard deviation (SD). Statistical analysis was performed using SPSS 23.0 (SPSS Inc. IL, New York, NY, USA). Multiple comparisons were evaluated using one-way or two-way ANOVA followed by Bonferroni's post hoc test. The DHI\% data were analyzed by two-way repeated-measures ANOVA followed by Bonferroni's post hoc test. A value of $P<0.05$ was considered statistically significant.

\section{Results}

\section{Identification of NPMSCs}

NPMSCs were isolated from the rat caudal intervertebral disc. After 5 days of culture, the primary cells exhibited a short spindle shape. The third generation of NPMSCs showed accelerated and spiral cell growth (Fig. 1a).

Multilineage differentiation ability of NPMSCs was performed in the third generation of NPMSCs. After induction for 21 days, Alizarin Red staining showed the formation of mineralized nodules after osteogenic differentiation induction. Alcian Blue staining was used showed distinct sulfurated 
proteoglycan staining after chondrogenic differentiation induction. Oil Red $\mathrm{O}$ staining showed lipid vacuoles formation after adipogenic differentiation induction. These results suggested that NPMSCs possess the ability of tri-lineage differentiation (Fig. 1b). Flow cytometry results exhibited that the expression of CD73, CD90, and CD105 were positive (more than 95\%) and CD34, CD45 were negative (less than 5\%) in NPMSCs (Fig. 1c), which was consistent with the standardized cell surface markers of mesenchymal stem cells[31].

\section{$75 \mu \mathrm{M} \mathrm{H}_{2} \mathrm{O}_{2}$ promoted the proliferation activity of NPMSCs via inhibiting the Hippo signaling pathway}

CCK-8 experiment showed that $75 \mu \mathrm{M}$ and $100 \mu \mathrm{M} \mathrm{H}_{2} \mathrm{O}_{2}$ treatments could significantly improve the proliferation of NPMSCs, whereas $300 \mu \mathrm{M} \mathrm{H}_{2} \mathrm{O}_{2}$ dramatically inhibited the proliferation ability of NPMSCs (Fig. 2a). The results of EdU staining showed that after $75 \mu \mathrm{M} \mathrm{H}_{2} \mathrm{O}_{2}$ treatment, the percentage of EdU positive cells increased significantly, while $300 \mu \mathrm{M} \mathrm{H}_{2} \mathrm{O}_{2}$ could reduce the percentage of EdU positive cells (Fig. 2b,2c). Western blot results showed that $75 \mu \mathrm{M} \mathrm{H}_{2} \mathrm{O}_{2}$ treatment elevated the expression of cyclin D1 and suppressed the expression of cyclin dependent kinase inhibitor 2A (P16). In comparison, $300 \mu \mathrm{M}$ $\mathrm{H}_{2} \mathrm{O}_{2}$ treatment significantly inhibited the expression of cyclin D1 and significantly raised the expression of P16 (Fig. 2d, 2e). These results showed that $75 \mu \mathrm{M} \mathrm{H}_{2} \mathrm{O}_{2}$ could promote the proliferation of NPMSCs.

The Hippo pathway is a crucial signaling pathway that can regulate cell proliferation and cell growth[27]. We speculated that $\mathrm{H}_{2} \mathrm{O}_{2}$ may regulate the proliferation of NPMSCs by inhibiting the Hippo pathway. Western blotting results showed that $75 \mathrm{\mu M} \mathrm{H}_{2} \mathrm{O}_{2}$ treatment reduced the phosphorylation levels of key proteins in the Hippo pathway including phosphorylated large tumor suppressor kinase 1 (p-Mst 1), phosphorylated mercaptopyruvate sulfurtransferase-1 ( $p$-Lats1), and phosphorylated Yes1 associated transcriptional regulator (p-YAP) (Fig. 2f, 2g). However, NPMSCs received $300 \mu \mathrm{M} \mathrm{H}_{2} \mathrm{O}_{2}$ treatment exhibited an opposite result. These results confirmed our conjecture.

\section{$75 \mu \mathrm{M} \mathrm{H}_{2} \mathrm{O}_{2}$ pretreatment enhanced the anti-oxidative stress capacity in NPMSCs}

The intracellular ROS content was detected under different concentrations of $\mathrm{H}_{2} \mathrm{O}_{2}$ treatment by flow cytometry. In the pretreatment process, we found that with the elevation of $\mathrm{H}_{2} \mathrm{O}_{2}$ concentration, the intracellular ROS concentration also increased (Fig. 3a, 3b). However, NPMSCs received $75 \mu \mathrm{M} \mathrm{H}_{2} \mathrm{O}_{2}$ pretreatment for $12 \mathrm{~h}$ showed significantly lower ROS content when they were exposed to $300 \mu \mathrm{M}$ $\mathrm{H}_{2} \mathrm{O}_{2}$ again (Fig. 3c, 3d).

To further verify the protective effect of $75 \mu \mathrm{M} \mathrm{H}_{2} \mathrm{O}_{2}$ pretreatment on NPMSCs, the Mito-Tracker Red CMXRos probe was used to detect the mitochondrial membrane potential. The results showed that the 
fluorescence intensity of CMXRos in NPMSCs treated with $300 \mu \mathrm{M} \mathrm{H}_{2} \mathrm{O}_{2}$ was significantly reduced. But in NPMSCs received $75 \mu \mathrm{M} \mathrm{H}_{2} \mathrm{O}_{2}$ pretreatment, the fluorescence intensity was relatively more (Fig. 3e, 3f). In conclusion, these results suggest that NPMSCs pretreated with $75 \mu \mathrm{M} \mathrm{H}_{2} \mathrm{O}_{2}$ can protect mitochondria and improve the ability of cells to resist oxidative stress.

\section{$75 \mu \mathrm{M} \mathrm{H}_{2} \mathrm{O}_{2}$ pretreatment improved the resistance of NPMSCs to oxidative stress by inhibiting Brd4 and activating the Keap1-Nrf2 signaling pathway}

To explore the mechanism of enhanced resistance of NPMSCs to oxidative stress by $75 \mu \mathrm{M} \mathrm{H}_{2} \mathrm{O}_{2}$ pretreatment, we detected the expression of key proteins in the Keap1-Nrf2 signaling pathway, which can regulate the expression of a variety of antioxidant and anti-inflammatory genes[32]. Western blot results showed that when NPMSCs pretreated with $75 \mu \mathrm{M} \mathrm{H}_{2} \mathrm{O}_{2}$ were exposed to $300 \mu \mathrm{M} \mathrm{H}_{2} \mathrm{O}_{2}$, the expression level of Keap1 significantly declined and the expression level of Nrf2 dramatically rose compared to NPMSCs exposed to $300 \mu \mathrm{M} \mathrm{H}_{2} \mathrm{O}_{2}$ solely (Fig. 4a, 4b).

As an upstream regulatory molecule of the Keap1-Nrf2 signaling pathway, Brd4 can inhibit the activation of this pathway and elevate the intracellular oxidative stress[33,34]. We found that $\mathrm{Brd} 4$ expression of NPMSCs pretreated with $75 \mu \mathrm{M} \mathrm{H}_{2} \mathrm{O}_{2}$ decreased significantly when they were exposed to $300 \mu \mathrm{M} \mathrm{H}_{2} \mathrm{O}_{2}$ (Fig. 4c, 4d). Therefore, we speculated that $75 \mathrm{\mu M} \mathrm{H}_{2} \mathrm{O}_{2}$ pretreatment could inhibit Brd4 expression and then activate the Keap1-Nrf2 signaling pathway in NPMSCs. Furthermore, we treated the $75 \mu \mathrm{M} \mathrm{H}_{2} \mathrm{O}_{2}$ pretreated NPMSCs with a Brd4 inhibitor JQ-1 (13030, MCE, Shanghai, China) and then exposed the cells to $300 \mu \mathrm{M} \mathrm{H}_{2} \mathrm{O}_{2}$. Western blot results showed that the Brd4 expression of cells in JQ-1 treatment group and $75 \mu \mathrm{M} \mathrm{H}_{2} \mathrm{O}_{2}$ pretreatment group tremendously decreased. Meanwhile, the expression level of Keap1 was significantly decreased and the expression level of Nrf2 was significantly elevated (Fig. 4e, 4f), which partially verified our speculation.

\section{$75 \mu \mathrm{M} \mathrm{H}_{2} \mathrm{O}_{2}$ pretreatment enhanced the anti-apoptotic capacity in NPMSCs}

We further explored the effect of $\mathrm{H}_{2} \mathrm{O}_{2}$ pretreatment on the anti-apoptotic ability of NPMSCs. The results of flow cytometry showed that when the concentration of $\mathrm{H}_{2} \mathrm{O}_{2}$ was less than $150 \mu \mathrm{M}$, there was no statistically significant change in the percentage of apoptosis of NPMSCs. The percentage of apoptosis increased when NPMSCs were treated with $200 \mu \mathrm{M}$ and $300 \mu \mathrm{M} \mathrm{H}_{2} \mathrm{O}_{2}$ (Fig. 5a, 5b). However, when NPMSCs received pretreatment with $75 \mu \mathrm{M} \mathrm{H}_{2} \mathrm{O}_{2}$ for $12 \mathrm{~h}$, the percentage of apoptotic cells was significantly reduced when they were subsequently exposed to $300 \mu \mathrm{M} \mathrm{H}_{2} \mathrm{O}_{2}$ (Fig. 5c, 5d). These results 
indicate that pretreatment with $75 \mu \mathrm{M} \mathrm{H}_{2} \mathrm{O}_{2}$ for $12 \mathrm{~h}$ can significantly improve the anti-apoptotic ability of NPMSCs.

Oxidative stress can lead to mitochondrial damage and mitochondrial apoptosis[35]. Therefore, we examined the effects of different concentrations of $\mathrm{H}_{2} \mathrm{O}_{2}$ on mitochondrial apoptosis-related proteins. The results showed that $75 \mu \mathrm{M} \mathrm{H}_{2} \mathrm{O}_{2}$ treatment exhibited the highest ratio of $\mathrm{Bcl}-2$ to Bax. And over 100 $\mu \mathrm{M} \mathrm{H}_{2} \mathrm{O}_{2}$ concentration could lead to distinctly increased Cytochrome $\mathrm{C}$. Increased cleaved-caspase 3 levels were observed when the concentrations of $\mathrm{H}_{2} \mathrm{O}_{2}$ exceeded $150 \mu \mathrm{M}$ (Fig. 5e,5f). However, compared with $300 \mu \mathrm{M} \mathrm{H}_{2} \mathrm{O}_{2}$ treated NPMSCs, NPMSCs pretreated with $75 \mu \mathrm{M} \mathrm{H}_{2} \mathrm{O}_{2}$ demonstrated elevated Bcl2/Bax ratio and declined cleaved-caspase 3 and suppressed Cytochrome $C$ when they were subsequently exposed to $300 \mu \mathrm{M} \mathrm{H}_{2} \mathrm{O}_{2}$ (Fig. 5g,5h). These results suggest that pretreatment of NPMSCs with $75 \mu \mathrm{M}$ $\mathrm{H}_{2} \mathrm{O}_{2}$ may enhance the ability of cells to resist apoptosis by stabilizing the mitochondrial.

\section{$75 \mu \mathrm{M} \mathrm{H}_{2} \mathrm{O}_{2}$ pretreatment promoted the therapeutic effects of transplanted NPMSCs in treating IVDD}

To explore whether NPMSCs pretreated with appropriate concentration of $\mathrm{H}_{2} \mathrm{O}_{2}$ can better adapt to the microenvironment of the degenerated intervertebral disc and thus result in ideal therapeutic effects in treating IVDD, A rat IVDD model and GFP-labeled NPMSCs were created. GFP protein was successfully overexpressed in NPMSCs to trace the transplanted cells (Fig. 6a). Next, NPMSCs pretreated with or without $75 \mu \mathrm{M} \mathrm{H}_{2} \mathrm{O}_{2}$ were injected into the degenerative intervertebral discs, and X-rays were taken at the 1st, 10th, 30th, and 60th days after transplantation (Fig. 6b). The DHI\% of rat caudal intervertebral disc was calculated according to the previously reported calculation method[10] (Fig. 6c). On day 60, we found that both groups with cell transplantation showed an increase in DHI\% compared to the untreated group (DHI\% $=49.00 \pm 1.52)$ and PBS injection group (DHI\% $=46.57 \pm 4.00)$. The treatment effect of the pretreated cell group $(\mathrm{DHI} \%=90.00 \pm 4.55)$ was better than that of the normal cell group $(\mathrm{DHI} \%=69.51 \pm$ 3.31) (Fig. 6d).

The histological structure of the NP tissue at 60 days after transplantation was analyzed by HE staining, Safranine O-Fast Green staining, and histological scores of IVDD (Fig. 6e, f). Reduced disc contents and disordered fibrous tissue were observed in the untreated group and the PBS group. Compared to the untreated group, the histological scores of the normal cell group and the pretreated cell group were higher, while the pretreated cell group exhibited the optimal ameliorative outcome.

In vivo fluorescence images results showed that obvious fluorescence could be observed in the caudal intervertebral disc of both groups of rats transplanted with NPMSCs. The fluorescence intensity of the rats injected with NPMSCs pretreated with $75 \mathrm{\mu M} \mathrm{H}_{2} \mathrm{O}_{2}$ was higher than that of the normal cells group (Fig. $6 \mathrm{~g}, 6 \mathrm{~h}$ ). These results suggest that $75 \mu \mathrm{M} \mathrm{H}_{2} \mathrm{O}_{2}$ pretreatment promoted the therapeutic effects of transplanted NPMSCs in treating IVDD. 


\section{Discussion}

Although many studies have reported that stem cell transplantation is a feasible method in the treatment of IVDD, the insufficient efficiency of transplantation and low survival rate of graft limit the therapeutic potential of this method to some extent[13,36]. A high concentration of $\mathrm{H}_{2} \mathrm{O}_{2}$ can induce a surge of intracellular ROS, which damages the organelles and results in cell cycle arrest and cell apoptosis[27]. However, pretreatment of transplanted cells with $\mathrm{H}_{2} \mathrm{O}_{2}$ at appropriate concentrations can result in beneficial effects. For example, pretreatment with $\mathrm{H}_{2} \mathrm{O}_{2}$ enhanced the anti-apoptotic ability of BMMSCs in skin wound[24,37]. $\mathrm{H}_{2} \mathrm{O}_{2}$ pretreatment of human umbilical cord mesenchymal stem cells (UCMSCs) or human ADMSCs improved the ability of cells to resist high dose $\mathrm{H}_{2} \mathrm{O}_{2}$ induced oxidative stress[38, 39]. In this study, we explored whether pretreating NPMSCs with $\mathrm{H}_{2} \mathrm{O}_{2}$ can improve the therapeutic efficacy of transplanted NPMSCs in IVDD and identify the optimal concentration. We found that $75 \mathrm{\mu M} \mathrm{H}_{2} \mathrm{O}_{2}$ pretreated NPMSCs demonstrated the strongest elevated cell proliferation, enhanced anti-oxidative stress ability, and distinctly reduced apoptosis. In vivo experiments results verified that 75 $\mu \mathrm{M} \mathrm{H}_{2} \mathrm{O}_{2}$ pretreated NPMSCs transplantation exhibited distinctly enhanced $\mathrm{DHI} \%$ and better histological morphology. These results demonstrate that $75 \mu \mathrm{M} \mathrm{H}_{2} \mathrm{O}_{2}$ is an optimal concentration in facilitating the therapeutic potential of NPMSCs transplantation in IVDD treatment.

Stem cells reported to treat IVDD include induced pluripotent stem cells (iPSCs), BMMSCs, ADSCs, and NPMSCs, etc.[8, 13,40]. NPMSCs are derived from nucleus pulposus tissue and are better able to survive in the microenvironment of the intervertebral disc and replenish the number of cells in the intervertebral disc. NPMSCs are stem cells derived from nucleus pulposus tissue which regarded as a more suitable candidate for transplantation in IVDD treatment. NPMSCs can survive better in the microenvironment of the degenerated intervertebral disc and replenish the residual nucleus pulposus cells[15, 40, 41]. Therefore, NPMSCs were selected as research objects in our study. NPMSCs were isolated from the nucleus pulposus tissue of rats. We observed that these cells could proliferate and grow adherent in a cell culture flask. Besides, these cells expressed CD34 and CD45 at low levels and CD73, CD90, and CD105 at high levels, which were consistent with the standardized cell surface markers of mesenchymal stem cells[31]. Furthermore, these cells could undergo tri-lineage differentiation. All of the above characteristics indicated that these cells fit the characteristics of mesenchymal stem cells[31].

To determine the optimal concentration of $\mathrm{H}_{2} \mathrm{O}_{2}$ for NPMSCs pretreatment, NPMSCs were cultured with different concentrations of $\mathrm{H}_{2} \mathrm{O}_{2}$ for $12 \mathrm{~h}$ according to the previous article reports[24]. Firstly, the cell viability and cell proliferation of NPMSCs were detected. We found that $50 \mu \mathrm{M}, 75 \mu \mathrm{M}$, and $100 \mu \mathrm{M} \mathrm{H} \mathrm{H}_{2} \mathrm{O}_{2}$ promoted the cell viability and cell proliferation of NPMSCs, when the $200 \mu \mathrm{M} \mathrm{H}_{2} \mathrm{O}_{2}$ and $300 \mu \mathrm{M}$ $\mathrm{H}_{2} \mathrm{O}_{2}$ inhibited the cell viability and cell proliferation of NPMSCs. Among the designated concentrations, $75 \mathrm{MM} \mathrm{H}_{2} \mathrm{O}_{2}$ treated NPMSCs exhibited the highest facilitating effects. Moreover, the expression of cyclin D1, reported as one of cell proliferation facilitators[42, 43], as well as P16, a well-known cell cycle repressor[44], were detected to consolidate our results. Consistent with the above observations, we found that $75 \mathrm{\mu M} \mathrm{H}_{2} \mathrm{O}_{2}$ treated NPMSCs exhibited maximized expression of cyclin D1 and lowest expression of 
P16, whereas the expression of cyclin D1 was decreased and the expression of P16 was elevated to the greatest extent in $300 \mu \mathrm{M} \mathrm{H}_{2} \mathrm{O}_{2}$ treated NPMSCs. Therefore, $75 \mu \mathrm{M} \mathrm{H}_{2} \mathrm{O}_{2}$ was selected as the pretreatment concentration and $300 \mu \mathrm{M} \mathrm{H}_{2} \mathrm{O}_{2}$ was selected as the concentration to induce inhibition of cell proliferation in subsequent experiments.

The Hippo pathway plays an important role in regulating stem cell proliferation and apoptosis[45, 46]. Previous studies have shown that the activated Hippo pathway can inhibit cell proliferation and promote cell apoptosis of the intervertebral disc cells[47-50]. Moreover, the inhibition of the Hippo pathway is closely related to the $\mathrm{H}_{2} \mathrm{O}_{2}$ induced BMMSCs proliferation upregulation and apoptosis downregulation[51]. Therefore, the expression of key proteins in the Hippo pathway were detected to explore the mechanism of $\mathrm{H}_{2} \mathrm{O}_{2}$ in promoting NPMSCs proliferation. We found that $75 \mu \mathrm{M} \mathrm{H}_{2} \mathrm{O}_{2}$ treatment significantly reduced the phosphorylation of Lats1, Mst1, and YAP, indicating that the Hippo pathway was inhibited. However, when NPMSCs received $300 \mu \mathrm{M} \mathrm{H}_{2} \mathrm{O}_{2}$ pretreatment, the phosphorylation of key proteins in this pathway decreased, indicating that the $75 \mu \mathrm{M} \mathrm{H}_{2} \mathrm{O}_{2}$ pretreatment may promote NPMSCs proliferation via inhibiting the Hippo pathway to some extent.

Oxidative stress is one of the key factors leading to cell damage in the intervertebral disc. ROS generated by intracellular metabolism can cause mitochondrial homeostasis loss and induce cell death[52-54]. We found that with increasing $\mathrm{H}_{2} \mathrm{O}_{2}$ concentration, the intracellular ROS content increased gradually.

However, we found that $75 \mu \mathrm{M} \mathrm{H}_{2} \mathrm{O}_{2}$ pretreated NPMSCs exhibited a distinct suppressed ROS level and upregulated mitochondrial membrane potential when they were supplemented with subsequent $300 \mu \mathrm{M}$ $\mathrm{H}_{2} \mathrm{O}_{2}$. These outcomes indicate that NPMSCs can activate their own antioxidant system after pretreatment and thus reducing the content of ROS in cells when they encounter detrimental $300 \mu \mathrm{M}$ $\mathrm{H}_{2} \mathrm{O}_{2}$. The Keap1-Nrf2 signaling pathway is the most important antioxidant system in cells. Activated Nrf2 can promote the expression of antioxidant factors such as $\mathrm{NAD}(\mathrm{P}) \mathrm{H}$ quinone dehydrogenase 1 (NQ01), superoxide dismutase (SOD), etc.[35, 55,56]. Previous studies have shown that activating the Keap1-Nrf2 signaling pathway could protect intervertebral disc cells from the oxidative stress injury[57, 58]. Therefore, we then explored whether the declined ROS and raised mitochondrial membrane potential were associated with the activation of the Keap1-Nrf2 signaling pathway. Our results found that that 75 $\mu \mathrm{M}$ pretreated $\mathrm{H}_{2} \mathrm{O}_{2}$ exhibited enhanced expression of $\mathrm{Nrf2}$, and reduced expression of Keap1 when they were supplemented with subsequent $300 \mu \mathrm{M} \mathrm{H}_{2} \mathrm{O}_{2}$. Interestingly, when NPMSCs were treated with $75 \mu \mathrm{M}$ of $\mathrm{H}_{2} \mathrm{O}_{2}, \mathrm{Brd} 4$, an upstream regulator of the Keap1-Nrf2 signaling pathway, was also decreased.

Therefore, we hypothesized that the $75 \mathrm{\mu M} \mathrm{H}_{2} \mathrm{O}_{2}$ pretreatment might also regulate Brd4. Subsequently, we treated NPMSCs with the Brd4 inhibitor JQ-1. JQ-1 treated NPMSCs and $75 \mu \mathrm{M} \mathrm{H}_{2} \mathrm{O}_{2}$ pretreated NPMSCs exhibited similar change trends in the expression level of Brd4, Keap1, and Nrf2, which partially confirmed our hypothesis.

Meanwhile, the apoptotic rate of NPMSCs under different $\mathrm{H}_{2} \mathrm{O}_{2}$ concentrations was detected. We found that $75 \mu \mathrm{M} \mathrm{H}_{2} \mathrm{O}_{2}$ treated NPMSCs exhibited the lowest cell apoptotic rate, while $300 \mu \mathrm{M} \mathrm{H}_{2} \mathrm{O}_{2}$ treated 
NPMSCs exhibited the highest cell apoptotic rate. Moreover, $75 \mu \mathrm{M} \mathrm{H}_{2} \mathrm{O}_{2}$ pretreated NPMSCs exhibited a distinct suppressed cell apoptotic rate when they were supplemented with subsequent $300 \mu \mathrm{M} \mathrm{H}_{2} \mathrm{O}_{2}$. The ratio of anti-apoptotic protein $\mathrm{Bcl}-2$ to pro-apoptotic protein Bax is an important indicator of the degree of apoptosis mediated by the mitochondrial pathway[59]. The level of Cytochrome $\mathrm{C}$ is the gold standard for mitochondrial damage[60]. Therefore, the expression levels of $\mathrm{Bcl}-2, \mathrm{Bax}$, apoptotic marker cleavedcaspase 3 , and Cytochrome $C$ were detected. We found that the $75 \mu \mathrm{M} \mathrm{H}_{2} \mathrm{O}_{2}$ treated NPMSCs demonstrated the highest ratio of $\mathrm{Bcl}-2$ to $\mathrm{Bax}$, and the lowest leaved-caspase 3 and Cytochrome $\mathrm{C}$ levels. The NPMSCs received $300 \mu \mathrm{M} \mathrm{H}_{2} \mathrm{O}_{2}$ demonstrated the lowest ratio of $\mathrm{Bcl}-2$ to $\mathrm{Bax}$, and the highest leaved-caspase 3 and Cytochrome $C$ levels. However, NPMSCs supplemented with $300 \mu \mathrm{M} \mathrm{H}_{2} \mathrm{O}_{2}$ exhibited an elevated ratio of $\mathrm{Bcl}-2$ to Bax, reduced leaved-caspase 3 and Cytochrome $\mathrm{C}$ levels if they were pretreated with $75 \mu \mathrm{M} \mathrm{H}_{2} \mathrm{O}_{2}$, which is consistent with the results above. These beneficial effects may also partly be attributed to the effects of $\mathrm{H}_{2} \mathrm{O}_{2}$ on the Hippo pathway and Keap1-Nrf2 pathway. Further research will illuminate the underlying mechanisms that $\mathrm{H}_{2} \mathrm{O}_{2}$ pretreatment regulates NPMSCs apoptosis. The signaling pathway involved in the $\mathrm{H}_{2} \mathrm{O}_{2}$ in regulating cell proliferation, oxidative stress, and cell apoptosis were summarized in Figure 7.

Based on the above in vitro study, we determined that $75 \mu \mathrm{M} \mathrm{H}_{2} \mathrm{O}_{2}$ pretreatment may maximize the proliferation and anti-apoptotic ability of NPMSCs. Therefore, we further explored whether $75 \mu \mathrm{M}$ $\mathrm{H}_{2} \mathrm{O}_{2}$ pretreatment NPMSCs could improve the therapeutic efficacy of NPMSCs transplantation in a rat IVDD model. As expected, compared to rats treated with normal cells alone, rats injected with $75 \mu \mathrm{M}$ $\mathrm{H}_{2} \mathrm{O}_{2}$ pretreated NPMSCs showed increased transplanted cells survival, facilitated extracellular matrix deposition, and a distinct improvement in DHI\% during a 60-day observation. Therefore, these results confirmed that NPMSCs pretreated with $75 \mu \mathrm{M} \mathrm{H}_{2} \mathrm{O}_{2}$ is an optimal concentration for NPMSCs pretreatment before transplantation. Notably, the optimal concentration of $\mathrm{H}_{2} \mathrm{O}_{2}$ pretreatment was slightly higher than that of previous studies[61, 62], This discrepancy may be attributed to the intrinsic feather of NPMSCs, which reside in a microenvironment of high mechanical pressure, low oxygen supplement, high lactic acid concentration. The NPMSCs may innately possess a certain resistance to $\mathrm{H}_{2} \mathrm{O}_{2}$.

There are several limitations in our experiment. Firstly, our experiment directly selected the time of $\mathrm{H}_{2} \mathrm{O}_{2}$ pretreatment reported before, thus the relationship between the therapeutic effects of $\mathrm{H}_{2} \mathrm{O}_{2}$ and pretreatment time was not explored. Time gradient experiment will further explore the optimal invention time to maximize the facilitating effects of $\mathrm{H}_{2} \mathrm{O}_{2}$ in the future. In addition, the underlying mechanisms that $\mathrm{H}_{2} \mathrm{O}_{2}$ pretreatment regulates the Hippo signaling pathway and Keap1-Nrf2 signaling pathway were not investigated in our current experiments, further molecular-level understanding of the experimental observations need to be explored in the future. However, the present experiments have proved the beneficial effects in $75 \mu \mathrm{M} \mathrm{H}_{2} \mathrm{O}_{2}$ in NPMSCs pretreatment. Given that this method is convenient and efficient, the $\mathrm{H}_{2} \mathrm{O}_{2}$ pretreated NPMSCs transplantation may become a feasible method in treating IVDD clinically in the future. 


\section{Conclusions}

In summary, we identified for the first time that pretreatment with $75 \mu \mathrm{M} \mathrm{H}_{2} \mathrm{O}_{2}$ can better promote cell proliferation, reduce oxidative stress and cell apoptosis in NPMSCs in vitro, which is related to the regulation of the Hippo signaling pathway and Keap1-Nrf2 pathway. NPMSCs pretreated with $75 \mu \mathrm{M}$ $\mathrm{H}_{2} \mathrm{O}_{2}$ also exhibited the most satisfactory therapeutic effects when transplanted in the rat degenerated caudal intervertebral disc. These results demonstrate that $75 \mu \mathrm{M} \mathrm{H}_{2} \mathrm{O}_{2}$ is an optimal concentration in NPMSCs pretreatment, which may serve as a feasible method for the clinical application of NPMSCsbased therapy in treating IVDD in the future.

\section{Abbreviations}

IVDD: intervertebral disc degeneration; NPMSCs: nucleus pulposus mesenchymal stem cells; $\mu \mathrm{M}$ : $\mu \mathrm{mol} / \mathrm{ml}$; h: hour; min: minute; $\mathrm{H}_{2} \mathrm{O}_{2}$ : hydrogen peroxide; Brd4: bromodomain containing 4; Keap1: kelchlike ECH-associated protein 1; Nrf2: nuclear factor, erythroid derived 2, like 2; LBP: low back pain; BMMSCs: bone marrow mesenchymal stem cells; SD rats: Sprague Dawley rats; PBS: phosphate buffer solution; OD: optical density; RIPA: radio-immunoprecipitation assay; PMSF: phenylmethanesulfonyl fluoride; BCA: bicinchoninic acid; PVDF: polyvinylidene fluoride; TBST: TBS with Tween-20; ROS: reactive oxygen species; GFP: green fluorescent protein; MOI: multiplicity of infection; C06-7: coccyx 6-7; SD: standard deviation; ANOVA: analysis of variance; UCMSCs: umbilical cord mesenchymal stem cells; ADMSCs: adipose mesenchymal stem cells; iPSCs: induced pluripotent stem cells; P16: cyclin dependent kinase inhibitor 2A; $\mathrm{p}$-Lats 1: phosphorylated large tumor suppressor kinase 1; $\mathrm{p}$-Mst 1: phosphorylated mercaptopyruvate sulfurtransferase-1; p-YAP: phosphorylated Yes1 associated transcriptional regulator; YAP: Yes1 associated transcriptional regulator; TAZ: tafazzin; ARE: antioxidant response elements; NQ01: $\mathrm{NAD}(\mathrm{P}) \mathrm{H}$ quinone dehydrogenase 1; SOD: superoxide dismutase.

\section{Declarations}

\section{Acknowledgments}

We thank Mr. Yang Zhang in our laboratory for technical assistance. Also, thanks to all the peer reviewers for their opinions and suggestions.

\section{Authors' contributions}

ZYY and LCQ conceived and designed the experiments; ZYY and HZL performed the experiments; GXX and $\mathrm{LCH}$ participated in the creation of the experimental animal model. LHY and CX revised the article and conducted the experiments complementation; ZY and LYY analyzed the data; ZYY and LJH edited the figures, LCQ polished the language. ZYY, ZY, and QYH wrote this article. LCQ and ZY reviewed and edited the article. 


\section{Funding}

This research was supported by the National Natural Science Foundation of China (Grant No. 81972113 and 82172488).

\section{Availability of data and materials}

All the data supporting the results were shown in the article and can be applicable from the corresponding author on reasonable request.

\section{Ethics approval and consent to participate}

Ethics approval was obtained with the informed consent of all participants. The Ethics Committee of the Army Medical University approved this research.

\section{Consent for publication}

Not applicable.

\section{Competing interests}

The authors declare no conflict of interest.

\section{References}

1. Jöud A, Petersson IF, Englund M. "Low back pain: epidemiology of consultations," (in eng). Arthritis Care Res (Hoboken). Jul 2012;64(7):1084-8.

2. BI Martin et al., "Expenditures and health status among adults with back and neck problems," (in eng), Jama, vol. 299, no. 6, pp. 656-64, Feb 132008.

3. Bowles RD, Setton LA. "Biomaterials for intervertebral disc regeneration and repair," (in eng), Biomaterials, vol. 129, pp. 54-67, Jun 2017.

4. Raj PP. "Intervertebral disc: anatomy-physiology-pathophysiology-treatment," (in eng), Pain practice: the official journal of World Institute of Pain, vol. 8, no. 1, pp. 18-44, Jan-Feb 2008.

5. Lo WC, Tsai LW, Yang YS, Chan RWY, "Understanding the Future Prospects of Synergizing Minimally Invasive Transforaminal Lumbar Interbody Fusion Surgery with Ceramics and Regenerative Cellular Therapies," Int J Mol Sci, vol. 22, no. 7, Mar 312021. 
6. BL Chen et al., "Surgical versus non-operative treatment for lumbar disc herniation: a systematic review and meta-analysis," (in eng), Clinical rehabilitation, vol. 32, no. 2, pp. 146-160, Feb 2018.

7. Clouet J, Fusellier M, Camus A, Le Visage C, Guicheux J, "Intervertebral disc regeneration: From cell therapy to the development of novel bioinspired endogenous repair strategies," (in eng), Advanced drug delivery reviews, vol. 146, pp. 306-324, Jun 2019.

8. Matta A, Karim MZ, Gerami H, Benigno B, Erwin WM. "A comparative study of mesenchymal stem cell transplantation and NTG-101 molecular therapy to treat degenerative disc disease," (in eng). Scientific reports. Jul 20 2021;11(1):14804.

9. C Yu et al. Injectable kartogenin and apocynin loaded micelle enhances the alleviation of intervertebral disc degeneration by adipose-derived stem cell. Bioact Mater. Oct 2021;6(10):3568-79.

10. Ma CJ, Liu X, Che L, Liu ZH, Samartzis D, Wang HQ, "Stem Cell Therapies for Intervertebral Disc Degeneration: Immune Privilege Reinforcement by Fas/FasL Regulating Machinery," (in eng), Current stem cell research \& therapy, vol. 10, no. 4, pp. 285-95, 2015.

11. Kregar Velikonja N, et al., "Cell sources for nucleus pulposus regeneration," (in eng), European spine journal: official publication of the European Spine Society, the European Spinal Deformity Society, and the European Section of the Cervical Spine Research Society, vol. 23 Suppl 3, pp. S364-74, Jun 2014.

12. W Wang et al., "Transplantation of Hypoxic-Preconditioned Bone Mesenchymal Stem Cells Retards Intervertebral Disc Degeneration via Enhancing Implanted Cell Survival and Migration in Rats," (in eng), Stem Cells Int, vol. 2018, p. 7564159, 2018.

13. RL Yim et al., "A systematic review of the safety and efficacy of mesenchymal stem cells for disc degeneration: insights and future directions for regenerative therapeutics," (in eng), Stem cells and development, vol. 23, no. 21, pp. 2553-67, Nov 12014.

14. Sakai D, Andersson GB, "Stem cell therapy for intervertebral disc regeneration: obstacles and solutions," (in eng), Nature reviews. Rheumatology, vol. 11, no. 4, pp. 243-56, Apr 2015.

15. B Han et al., "Nucleus pulposus mesenchymal stem cells in acidic conditions mimicking degenerative intervertebral discs give better performance than adipose tissue-derived mesenchymal stem cells," (in eng), Cells, tissues, organs, vol. 199, no. 5-6, pp. 342-52, 2014.

16. H Wu et al., "Comparison of nucleus pulposus stem/progenitor cells isolated from degenerated intervertebral discs with umbilical cord derived mesenchymal stem cells," (in eng), Experimental cell research, vol. 361, no. 2, pp. 324-332, Dec 152017.

17. Z Li et al., "Comparison of different methods for the isolation and purification of rat nucleus pulposus-derived mesenchymal stem cells," (in eng), Connective tissue research, vol. 61, no. 5, pp. 426-434, Sep 2020.

18. Bartels EM, Fairbank JC, Winlove CP, Urban JP. "Oxygen and lactate concentrations measured in vivo in the intervertebral discs of patients with scoliosis and back pain," (in eng), Spine, vol. 23, no. 1, pp. 1-7; discussion 8, Jan 11998.

19. Grunhagen T, Wilde G, Soukane DM, Shirazi-Adl SA, Urban JP, "Nutrient supply and intervertebral disc metabolism," (in eng), The Journal of bone and joint surgery. American volume, vol. 88 Suppl 2, 
pp. 30-5, Apr 2006.

20. Rudert M, Tillmann B. "Lymph and blood supply of the human intervertebral disc. Cadaver study of correlations to discitis," (in eng). Acta Orthop Scand. Feb 1993;64(1):37-40.

21. H Xing et al., "Injectable exosome-functionalized extracellular matrix hydrogel for metabolism balance and pyroptosis regulation in intervertebral disc degeneration," (in eng), Journal of nanobiotechnology, vol. 19, no. 1, p. 264, Sep 62021.

22. Y Zeng et al., "Injectable microcryogels reinforced alginate encapsulation of mesenchymal stromal cells for leak-proof delivery and alleviation of canine disc degeneration," (in eng), Biomaterials, vol. 59, pp. 53-65, Aug 2015.

23. F Colella et al., "Drug delivery in intervertebral disc degeneration and osteoarthritis: Selecting the optimal platform for the delivery of disease-modifying agents," (in eng), Journal of controlled release: official journal of the Controlled Release Society, vol. 328, pp. 985-999, Dec 102020.

24. L Guo et al., "Optimal H2O2 preconditioning to improve bone marrow mesenchymal stem cells' engraftment in wound healing" Stem Cell Research \& Therapy, vol. 11, no. 1, 2020.

25. N Liao et al. "Antioxidant preconditioning improves therapeutic outcomes of adipose tissue-derived mesenchymal stem cells through enhancing intrahepatic engraftment efficiency in a mouse liver fibrosis model". Stem Cell Res Ther. 2020;11(1):237.

26. J Zhang et al. "Hydrogen peroxide preconditioning enhances the therapeutic efficacy of Wharton's Jelly mesenchymal stem cells after myocardial infarction". Chin Med J. 2012;125(19):3472-8.

27. X Chi et al., "Protective Effect of Epigallocatechin-3-Gallate in Hydrogen Peroxide-Induced Oxidative Damage in Chicken Lymphocytes," (in eng), Oxid Med Cell Longev, vol. 2020, p. 7386239, 2020.

28. H Nakayama et al., "Protective Effect of Ferulic Acid against Hydrogen Peroxide Induced Apoptosis in PC12 Cells," (in eng), Molecules (Basel, Switzerland), vol. 26, no. 1, Dec 282020.

29. B Han et al., "A simple disc degeneration model induced by percutaneous needle puncture in the rat tail," (in eng), Spine, vol. 33, no. 18, pp. 1925-34, Aug 152008.

30. J Zhu et al. Sustained release of GDF5 from a designed coacervate attenuates disc degeneration in a rat model. Acta Biomater. Mar 1 2019;86:300-11.

31. M Dominici et al., "Minimal criteria for defining multipotent mesenchymal stromal cells. The International Society for Cellular Therapy position statement," Cytotherapy, vol. 8, no. 4, pp. 315-7, 2006.

32. Yu C, Xiao JH, "The Keap1-Nrf2 System: A Mediator between Oxidative Stress and Aging," Oxid Med Cell Longev, vol. 2021, p. 6635460, 2021.

33. M Hussong et al., "The bromodomain protein BRD4 regulates the KEAP1/NRF2-dependent oxidative stress response," Cell Death Dis, vol. 5, p. e1195, Apr 242014.

34. Zuo H, Wang S, Feng J, Liu X. "BRD4 contributes to high-glucose-induced podocyte injury by modulating Keap1/Nrf2/ARE signaling," (in eng), Biochimie, vol. 165, pp. 100-107, Oct 2019. 
35. Xiao Q, Piao R, Wang H, Li C, Song L. "Orientin-mediated Nrf2/HO-1 signal alleviates H(2)O(2)induced oxidative damage via induction of JNK and PI3K/AKT activation," (in eng), International journal of biological macromolecules, vol. 118, no. Pt A, pp. 747-755, Oct 152018.

36. Binch ALA, Fitzgerald JC, Growney EA, Barry F. "Cell-based strategies for IVD repair: clinical progress and translational obstacles," (in eng). Nat Rev Rheumatol. Mar 2021;17(3):158-75.

37. Li S, Deng Y, Feng J, Ye W, "Oxidative preconditioning promotes bone marrow mesenchymal stem cells migration and prevents apoptosis," (in eng), Cell biology international, vol. 33, no. 3, pp. 411-8, Mar 2009.

38. Garrido-Pascual P, Alonso-Varona A, Castro B, Buron M, Palomares T, "H2O2-preconditioned human adipose-derived stem cells (HC016) increase their resistance to oxidative stress by overexpressing Nrf2 and bioenergetic adaptation," Stem Cell Res Ther, vol. 11, no. 1, p. 335, Aug 32020.

39. Li D, Xu Y, Gao CY, Zhai YP, "Adaptive protection against damage of preconditioning human umbilical cord-derived mesenchymal stem cells with hydrogen peroxide," (in eng), Genetics and molecular research: GMR, vol. 13, no. 3, pp. 7304-17, Feb 212014.

40. YQ Tao et al., "Potential of co-culture of nucleus pulposus mesenchymal stem cells and nucleus pulposus cells in hyperosmotic microenvironment for intervertebral disc regeneration," (in eng), Cell biology international, vol. 37, no. 8, pp. 826-34, Aug 2013.

41. J Liu et al., "Biological Behavior of Human Nucleus Pulposus Mesenchymal Stem Cells in Response to Changes in the Acidic Environment During Intervertebral Disc Degeneration," (in eng), Stem cells and development, vol. 26, no. 12, pp. 901-911, Jun 152017.

42. MM Rahman et al., "Differential expression of phosphorylated MEK and ERK correlates with aggressive BCC subtypes," (in eng), Carcinogenesis, vol. 42, no. 7, pp. 975-983, Jul 162021.

43. Guo Y, Zhao N, Zhou J, Dong J, Wang X, "Sirtuin 2 in Endometrial Cancer: A Potential Regulator for Cell Proliferation, Apoptosis and RAS/ERK Pathway," (in eng), Technology in cancer research \& treatment, vol. 19, p. 1533033820980781, Jan-Dec 2020.

44. BG Childs et al. "Senescent cells: an emerging target for diseases of ageing," (in eng). Nat Rev Drug Discov. Oct 2017;16(10):718-35.

45. Nguyen-Lefebvre AT, Selzner N, Wrana JL, Bhat M. "The hippo pathway: A master regulator of liver metabolism, regeneration, and disease. FASEB J. May 2021;35(5):e21570.

46. Zhao B, Tumaneng K, Guan KL, "The Hippo pathway in organ size control, tissue regeneration and stem cell self-renewal," Nat Cell Biol, vol. 13, no. 8, pp. 877-83, Aug 12011.

47. Croft AS, Roth Y, Oswald KAC, Ćorluka S, Bermudez-Lekerika P, Gantenbein B. "In Situ Cell Signalling of the Hippo-YAP/TAZ Pathway in Reaction to Complex Dynamic Loading in an Intervertebral Disc Organ Culture" International Journal of Molecular Sciences, vol. 22, no. 24, 2021.

48. $\mathrm{H}$ Yang et al. "LncRNA JPX regulates proliferation and apoptosis of nucleus pulposus cells by targeting the miR-18a-5p/HIF-1alpha/Hippo-YAP pathway". Biochem Biophys Res Commun. Aug 20 2021;566:16-23. 
49. Y Wang et al., "Hydrostatic Pressure Modulates Intervertebral Disc Cell Survival and Extracellular Matrix Homeostasis via Regulating Hippo-YAP/TAZ Pathway," Stem Cells Int, vol. 2021, p. 5626487, 2021.

50. J Chen et al. "IL-6/YAP1/beta-catenin signaling is involved in intervertebral disc degeneration". J Cell Physiol. May 2019;234(5):5964-71.

51. Jeon S, Kim D, Cho J. "Neural precursor cell-expressed, developmentally down-regulated 4 (NEDD4) regulates hydrogen peroxide-induced cell proliferation and death through inhibition of Hippo signaling". FASEB journal: official publication of the Federation of American Societies for Experimental Biology. 2019;33(12):14772-83.

52. Y Hu et al., "Exosomes Derived from Bone Mesenchymal Stem Cells Alleviate Compression-Induced Nucleus Pulposus Cell Apoptosis by Inhibiting Oxidative Stress," (in eng), Oxid Med Cell Longev, vol. 2021, p. 2310025, 2021.

53. Foo BJ, Eu JQ, Hirpara JL, Pervaiz S, "Interplay between Mitochondrial Metabolism and Cellular Redox State Dictates Cancer Cell Survival," (in eng), Oxid Med Cell Longev, vol. 2021, p. 1341604, 2021.

54. Di Meo S, Reed TT, Venditti P, Victor VM, "Role of ROS and RNS Sources in Physiological and Pathological Conditions," (in eng), Oxid Med Cell Longev, vol. 2016, p. 1245049, 2016.

55. Schmidlin CJ, Dodson MB, Madhavan L, Zhang DD, "Redox regulation by NRF2 in aging and disease," (in eng), Free radical biology \& medicine, vol. 134, pp. 702-707, Apr 2019.

56. Dayalan Naidu S, Kostov RV, Dinkova-Kostova AT, "Transcription factors Hsf1 and Nrf2 engage in crosstalk for cytoprotection," (in eng), Trends in pharmacological sciences, vol. 36, no. 1, pp. 6-14, Jan 2015.

57. W Hua et al. "Icariin protects human nucleus pulposus cells from hydrogen peroxide-induced mitochondria-mediated apoptosis by activating nuclear factor erythroid 2-related factor 2". Biochim Biophys Acta Mol Basis Dis. Jan 1 2020;1866(1):165575.

58. $\mathrm{H}$ Zhu et al. "Dimethyl fumarate protects nucleus pulposus cells from inflammation and oxidative stress and delays the intervertebral disc degeneration". Exp Ther Med. Dec 2020;20(6):269.

59. Dadsena S, King LE, García-Sáez AJ, "Apoptosis regulation at the mitochondria membrane level," (in eng), Biochimica et biophysica acta. Biomembranes, vol. 1863, no. 12, p. 183716, Dec 12021.

60. Ma K, Chen G, Li W, Kepp O, Zhu Y, Chen Q, "Mitophagy, Mitochondrial Homeostasis, and Cell Fate," (in eng), Frontiers in cell and developmental biology, vol. 8, p. 467, 2020.

61. T Khatlani et al., "Preconditioning by Hydrogen Peroxide Enhances Multiple Properties of Human Decidua Basalis Mesenchymal Stem/Multipotent Stromal Cells," (in eng), Stem Cells Int, vol. 2018, p. 6480793, 2018.

62. KD Pendergrass et al., "Acute preconditioning of cardiac progenitor cells with hydrogen peroxide enhances angiogenic pathways following ischemia-reperfusion injury," (in eng), Stem cells and development, vol. 22, no. 17, pp. 2414-24, Sep 12013. 


\section{Figures}

\section{Figure 1}

Identification of NPMSCs. (a) Representative image illustrating the morphology of NPMSCs. Scale bar = $200 \mu \mathrm{m}$. (b) Alizarin Red staining, Alcian Blue staining, and Oil Red 0 staining results of NPMSCs at 21 days post induction. Scale bar $=50 \mu \mathrm{m}$. (c) Flow cytometry examining the expression of CD34, CD45, CD73, CD90 and CD105 on the NPMSCs.

\section{Figure 2}

Effects of different $\mathrm{H}_{2} \mathrm{O}_{2}$ concentrations on NPMSCs proliferation. (a) The effect of $\mathrm{H}_{2} \mathrm{O}_{2}$ on NPMSCs proliferation detected by the CCK-8 assay. $(n=3, * P<0.05$, $* * P<0.01$, one-way ANOVA followed by Bonferroni's post hoc test). (b, c) Detection of proliferated NPMSCs (red) under different $\mathrm{H}_{2} \mathrm{O}_{2}$ concentrations by the EdU-555 proliferation assay kit and quantification. Nuclei were counterstained with Hoechst 33358 (blue). ( $n=3,{ }^{*}<<0.05,{ }^{*} \mathrm{P}<0.01$, one-way ANOVA followed by Bonferroni's post hoc test). Scale bar $=200 \mu \mathrm{m}$. (d, e) Western blot analysis of cyclin D1 and P16 expressions in NPMSCs exposed to different concentrations of $\mathrm{H}_{2} \mathrm{O}_{2}$ for $12 \mathrm{~h}\left(\mathrm{n}=3,{ }^{*} \mathrm{P}<0.05\right.$, ${ }^{*} \mathrm{P}<0.01$, one-way ANOVA followed by Bonferroni's post hoc test). (f, g) Western blot analysis of p-Lats1, p-Mst1, p-YAP, and YAP expressions in NPMSCs exposed to different concentrations of $\mathrm{H}_{2} \mathrm{O}_{2}$ for $12 \mathrm{~h}$. $\left(n=3,{ }^{*} P<0.05,{ }^{*} P<0.01\right.$, one-way ANOVA followed by Bonferroni's post hoc test).

\section{Figure 3}

Effect of different $\mathrm{H}_{2} \mathrm{O}_{2}$ concentration $\mathrm{H}_{2} \mathrm{O}_{2}$ on ROS and mitochondrial membrane potential in NPMSCs. $(\mathbf{a}, \mathbf{b})$ The intracellular ROS in NPMSCs received different $\mathrm{H}_{2} \mathrm{O}_{2}$ concentration detected by flow cytometry and quantifications. ( $n=3,{ }^{*} P<0.05$, ${ }^{*} P<0.01$, one-way ANOVA followed by Bonferroni's post hoc test). (c, d) The intracellular ROS in NPMSCs received $75 \mu \mathrm{M} \mathrm{H}_{2} \mathrm{O}_{2}$ pretreatment detected by flow cytometry and quantifications. ( $n=3,{ }^{*} P<0.05,{ }^{*} \mathrm{P}<0.01$, one-way ANOVA followed by Bonferroni's post hoc test). (e, $\left.\mathbf{f}\right)$ The mitochondrial membrane potential of NPMSCs received $75 \mu \mathrm{M} \mathrm{H}_{2} \mathrm{O}_{2}$ pretreatment detected by Mitotracker Red CMXRos and quantifications. ( $n=3, * P<0.05$, $* * P<0.01$, one-way ANOVA followed by Bonferroni's post hoc test, \#\# $\mathrm{P}<0.01$ compared to the $300 \mu \mathrm{M} \mathrm{H}_{2} \mathrm{O}_{2}$ group). Scale bar $=50 \mu \mathrm{m}$. 
Effect of different $\mathrm{H}_{2} \mathrm{O}_{2}$ concentrations on the Keap1-Nrf2 signaling pathway in NPMSCs. (a, b) Western blot analysis of Keap1 and Nrf2 expressions in NPMSCs exposed to different concentrations of $\mathrm{H}_{2} \mathrm{O}_{2}$. $\left(n=3,{ }^{*} P<0.05,{ }^{*} P<0.01\right.$, one-way ANOVA followed by Bonferroni's post hoc test. \# $P<0.05$ compared to the $300 \mu \mathrm{M} \mathrm{H}_{2} \mathrm{O}_{2}$ group). (c, d) Western blot analysis of Brd4 expressions in NPMSCs exposed to different concentrations of $\mathrm{H}_{2} \mathrm{O}_{2}$. ( $n=3,{ }^{*} \mathrm{P}<0.05$, ${ }^{*} \mathrm{P}<0.01$, one-way ANOVA followed by Bonferroni's post hoc test. \# $\mathrm{P}<0.01$ compared to the $300 \mu \mathrm{M} \mathrm{H}_{2} \mathrm{O}_{2}$ group). (e, f) Western blot analysis estimating the effect of 75 $\mu \mathrm{M} \mathrm{H}_{2} \mathrm{O}_{2}$ pretreatment on Keap1, Nrf2, and Brd4 expression and quantification when NPMSCs were subsequently exposed to $300 \mu \mathrm{M} \mathrm{H}_{2} \mathrm{O}_{2}$ ( $n=3$, ${ }^{*} \mathrm{P}<0.05$, ${ }^{*} \mathrm{P}<0.01$, one-way ANOVA followed by Bonferroni's post hoc test. \#\# $\mathrm{P}<0.01$ compared to the $300 \mu \mathrm{M} \mathrm{H}_{2} \mathrm{O}_{2}$ group).

\section{Figure 5}

Effect of different $\mathrm{H}_{2} \mathrm{O}_{2}$ concentrations on the anti-apoptotic capacity of NPMSCs. (a, b) Effect of different $\mathrm{H}_{2} \mathrm{O}_{2}$ on the apoptosis ratio detected by flow cytometry and quantification. ( $n=3, * P<0.05$, $* * P<0.01$, one-way ANOVA followed by Bonferroni's post hoc test). (c, d) Effect of $75 \mu \mathrm{M} \mathrm{H}_{2} \mathrm{O}_{2}$ pretreatment on the apoptosis ratio detected by flow cytometry and quantification when NPMSCs were subsequently exposed to $300 \mu \mathrm{M} \mathrm{H}_{2} \mathrm{O}_{2}$ ( $n=3$, ${ }^{*} P<0.05$, ${ }^{*} \mathrm{P}<0.01$, one-way ANOVA followed by Bonferroni's post hoc test. \#\# $\mathrm{P}<0.01$ compared to the $300 \mu \mathrm{M} \mathrm{H}_{2} \mathrm{O}_{2}$ group). (e, f) Western blot analysis estimating the effect of different $\mathrm{H}_{2} \mathrm{O}_{2}$ on $\mathrm{Bcl}-2$, Bax, cleaved-caspase 3 , and Cytochrome $\mathrm{C}$ expression and quantification. ( $n=3,{ }^{*} P<0.05$, ${ }^{*} P<0.01$, one-way ANOVA followed by Bonferroni's post hoc test). $(\mathbf{g}, \mathbf{h})$ Western blot analysis estimating the effect of $75 \mu \mathrm{M} \mathrm{H}_{2} \mathrm{O}_{2}$ pretreatment on Bcl-2, Bax, cleaved-caspase 3, and Cytochrome $C$ expression and quantification when NPMSCs were subsequently exposed to $300 \mu \mathrm{M}$ $\mathrm{H}_{2} \mathrm{O}_{2}(\mathrm{n}=3, * \mathrm{P}<0.05$, $* * \mathrm{P}<0.01$, one-way ANOVA followed by Bonferroni's post hoc test. \# $\mathrm{P}<0.05$, \#\# $\mathrm{P}<$ 0.01 compared to the $300 \mu \mathrm{M} \mathrm{H}_{2} \mathrm{O}_{2}$ group).

\section{Figure 6}

$75 \mu \mathrm{M} \mathrm{H}_{2} \mathrm{O}_{2}$ pretreatment facilitated the therapeutic effects of transplanted NPMSCs in treating IVDD. (a) GFP protein was overexpressed in NPMSCs utilizing lentiviral vectors to trace the transplanted cells. Scale bar $=200 \mu \mathrm{m}$. (b) Representative X-rays images were taken on the $0,1 \mathrm{st}, 10$ th, 30th, and 60th days after injection. (c) Methods of calculating DHI\%. (d) Quantification of DHI\% in rats on designated days after treatment. ( $n=6$, two-way repeated-measures ANOVA followed by Bonferroni's post hoc test. ${ }^{*} \mathrm{P}<0.01$, \#\# $\mathrm{P}<0.01$, compared to the normal cells group). (e) Representative HE staining and Safranine O-Fast Green staining illustrating the histological structure of the NP tissue at 60 days after treatment. Scale bar $=500 \mu \mathrm{m}$. (f) Histological score of the intervertebral disc in each group ( $n=3,{ }^{\star *} P<0.01$, one-way ANOVA followed by Bonferroni's post hoc test, \# P<0. 0 5, compared to the normal cells group). $(\mathbf{g}, \mathbf{h}) 60$ 
days after treatment, the fluorescence intensity of GFP-labeled NPMSCs in intervertebral discs was detected by the multi-mode small animal live imaging system $(n=3, * \star P<0.01$, one-way ANOVA followed by Bonferroni's post hoc test, \#\# $\mathrm{P}<0.01$, compared to the normal cells group).

\section{Figure 7}

Signaling pathway involved in the $\mathrm{H}_{2} \mathrm{O}_{2}$ in regulating cell proliferation, oxidative stress, and cell apoptosis in NPMSCs. Optimal concentration of $\mathrm{H}_{2} \mathrm{O}_{2}: 75 \mu \mathrm{M}$; The lethal concentration of $\mathrm{H}_{2} \mathrm{O}_{2}: 300 \mu \mathrm{M}$. Up arrow: upregulation. Down arrow: downregulation.

\section{Supplementary Files}

This is a list of supplementary files associated with this preprint. Click to download.

- renamed70c2b.docx 